\title{
COMPARATIVE STUDY OF MULTIDETECTOR COMPUTED TOMOGRAPHY AND ULTRASONOGRAPHY FINDINGS IN BLUNT ABDOMINAL TRAUMA
}

\author{
Okram Pusparani Devi' ${ }^{1}$ Yengkhom Rameshwor Singh ${ }^{2}$, Tonjam Hemchand Singh ${ }^{3}$
}

${ }^{1}$ Assistant Professor, Department of Radiodiagnosis, JNIMS, Imphal.

${ }^{2}$ Assistant Professor, Department of Paediatrics, JNIMS, Imphal.

${ }^{3}$ Assistant Professor, Department of Psychiatry, JNIMS, Imphal.

\section{ABSTRACT}

\section{BACKGROUND}

Blunt abdominal trauma usually has low sensitivity on physical examination and also subtle clinical manifestations. Improved resolution of the ultrasound machines and availability of multiple frequency probes has improved the specificity of ultrasound evaluation in blunt abdominal trauma. Despite this about $50 \%$ of the solid organ injuries are missed. Computed tomography has been used with better specificity to evaluate patients with blunt abdominal trauma who are FAST (Focused Assessment with Sonography for Trauma) positive as well as indeterminate and clinically suspicious cases of solid organ, hollow viscera, spine and pelvic injury.

\section{AIM AND OBJECTIVES}

The purpose of this study was to determine sensitivity, specificity and diagnostic accuracy of USG and MDCT and compare the efficacy of the two imaging modalities in blunt abdominal trauma.

\section{METHOD}

A prospective observational study of 100 patients was conducted in the Department of Radiodiagnosis, Bharati Hospital, Pune. All patients with blunt abdominal trauma were included. FAST screening was done with ANTARES ACUSON SIEMENS followed by MDCT on 16-Slice Philips Brilliance. Sensitivity, specificity and diagnostic accuracy of USG and CT were determined by comparing with laparotomy findings.

\section{RESULTS}

Although USG was sensitive, specific and accurate in detecting free fluid in abdomen, CT was found better and also superior in detecting solid organ injury in patients with blunt abdominal trauma.

\section{CONCLUSION}

Ultrasound is an efficient modality in the initial evaluation of blunt abdominal trauma. But CT is the superior diagnostic modality and must be performed in symptomatic patient with ultrasound negative report and suboptimal ultrasound examination. CT scan thoroughly scrutinizes entire abdomen including retroperitoneum with additional assessment of thoracic trauma and bony pelvic trauma. Hence, CT increases diagnostic confidence and influences management decision.

\section{KEYWORDS}

Blunt Abdominal Trauma, MDCT, USG, FAST.

HOW TO CITE THIS ARTICLE: Devi OP, Singh YR, Singh TH. Comparative study of multidetector computed tomography and ultrasonography findings in blunt abdominal trauma. J. Evolution Med. Dent. Sci. 2016;5(61):4305-4308, DOI: $10.14260 /$ jemds/2016/982

\section{INTRODUCTION}

Ultrasound is rapid, reliable, cost effective and easily available imaging modality with unique ability to detect free fluid in abdomen.(1) Comprehensive evaluation of actively injured patient is frequently impossible due to rib fracture, wounds and gaseous distension of bowel. CT is not only sensitive and specific, but also provides global evaluation of abdomen and retroperitoneum. CT provides exact location of injury and its extent, so trend towards conservative management of liver, spleen and kidney injuries is increasing and also number of negative laparotomies are reduced.(2)

Financial or Other, Competing Interest: None.

Submission 16-06-2016, Peer Review 18-07-2016,

Acceptance 23-07-2016, Published 01-08-2016.

Corresponding Author:

Dr. Okram Pusparani Devi,

C/o. Dr. Yengkhom Rameshwor Singh,

Thoubal Haokha, Maning Leikai,

P.O. Thoubal, Manipur- 795138.

E-mail: drpuspaokram@gmail.com

DOI: $10.14260 /$ jemds/2016/982
"Focused Assessment with Sonography for Trauma" (FAST) is a method to detect intraperitoneal fluid in an emergency setting. Second generation ultrasound with improved resolution and multiple frequency probes improve the specificity of ultrasound evaluation in blunt abdominal trauma. $(3,4)$ Even with improved ultrasound machines about $50 \%$ of the solid organ injuries are missed, hence cannot replace CT. Computed tomography has been introduced to evaluate patients with blunt abdominal trauma among the FAST positive, indeterminate and clinically suspicious cases of solid organ, hollow viscera, spine and pelvis injury. $(5,6)$

\section{AIM AND OBJECTIVES}

The purpose of this study was to evaluate sensitivity, specificity and diagnostic efficacy of USG and CT in detecting free fluid in abdomen and abdominal organ injuries in patients with blunt abdominal trauma and then compare the sensitivity, specificity and diagnostic accuracy of the two imaging modalities in detecting free fluid in abdomen and abdominal organ injury. 


\section{MATERIALS AND METHOD}

A prospective observational study of 100 patients of blunt abdominal trauma with suspected abdominal organ injury was conducted over a period of 2 years from July 2010 to August 2012 in the Department of Radiodiagnosis and Imaging, Bharati Hospital, Pune. Ethical clearance was taken from College Ethical Committee. Informed written consent was taken from patient or relative.

FAST screening was done with ANTARES ACUSON SIEMENS followed by MDCT study on 16 SLICE PHILIPS BRILLIANCE.

\section{USG Technique}

FAST was done as a quick screening test and abdomen was screened for free fluid in peritoneal cavity and abdominal organ injuries.

\section{CT Scan Technique}

Scan protocol: 120-140 KVP, 200-250 mAs, Pitch 1.5, Field of view 240-300 mm, Collimation $2.5 \mathrm{~mm}$ ( $3.2 \mathrm{~mm}$ effective). Initially unenhanced images of the abdomen and pelvis were obtained. Subsequently, non-ionic contrast of concentration $400 \mathrm{mg} / \mathrm{mL}$ was administered at $1.5 \mathrm{~mL} / \mathrm{kg}$ body weight in adults and children, and was injected @ 2-3 mL/second through intravenous cannula using a pressure injector. Multiphase contrast study was done in each patient.

The findings of USG were compared with those of MDCT in detail. Confirmatory correlation was made with laparotomy findings in available cases. Statistical analysis was performed pertaining to sensitivity, specificity and diagnostic accuracy of USG and MDCT separately and the two results were compared.

Statistical analysis was done using the formula: Sensitivity=true positive/(true positive + false negative) $\mathrm{x} 100$, Specificity=true negative/(true negative + false positive) $x 100$, Diagnostic accuracy $=$ (true negative + true positive) $/$ (true negative + true positive + false negative + false positive).

\section{RESULT}

Of the total 100 patients, 52 patients were in the age group of 21-40 years, which is the most active span of life. Of 100 patients, 78 were male and 22 were female with male:female ratio of 3.5:1 and the most common mode of trauma was road traffic accident $(66 \%)$ followed by fall from height (28\%). Of all the patients, $90 \%$ had abdominal organ injury and haemoperitoneum was found in $90 \%$ of cases.

The most common organs injured were spleen and liver, 34 patients each followed by kidney 24 patients. USG showed sensitivity of $100 \%$, specificity of $62.5 \%$ and overall diagnostic accuracy of $94 \%$ as compared to that of CT, which showed $100 \%$ sensitivity, $100 \%$ specificity and diagnostic accuracy of $100 \%$ for detection of free intraperitoneal fluid. Also, USG showed sensitivity of $68.8 \%$, specificity of $80 \%$ and overall diagnostic accuracy of $70 \%$ as compared to CT which showed $97.7 \%$ sensitivity, $100 \%$ specificity and overall diagnostic accuracy of $98 \%$ for detection of abdominal organ injuries.

\begin{tabular}{|c|c|c|c|c|}
\hline Sl. No. & Age Group (Years) & Male & Female & Total \\
\hline 1 & $0-10$ & 12 & 8 & 20 \\
\hline 2 & $11-20$ & 12 & 2 & 14 \\
\hline 3 & $21-30$ & 30 & 4 & 34 \\
\hline 4 & $31-40$ & 12 & 6 & 18 \\
\hline 5 & $41-50$ & 6 & 0 & 6 \\
\hline 6 & $51-60$ & 6 & 0 & 6 \\
\hline 7 & $61-70$ & 0 & 0 & 0 \\
\hline 8 & $71-80$ & 0 & 2 & 2 \\
\hline \multicolumn{4}{|c|}{ Table 1: Age and Sex Distribution (n=100) } \\
\hline \multicolumn{4}{|c|}{} \\
\hline
\end{tabular}

\begin{tabular}{|c|c|c|}
\hline Sl. No. & Mode of Trauma & No. of Patients \\
\hline 1 & Road traffic accident & 66 \\
\hline 2 & Fall from height & 28 \\
\hline 3 & $\begin{array}{c}\text { Fall of heavy object on } \\
\text { abdomen }\end{array}$ & 4 \\
\hline 4 & Others & 2 \\
\hline \multicolumn{3}{|c|}{ Total } \\
\hline \multicolumn{2}{|c|}{ Table 2: Distribution of Patients According to Mechanism } \\
of Injury (n=100) \\
\hline
\end{tabular}

\begin{tabular}{|c|c|c|c|c|}
\hline $\begin{array}{l}\text { Sl. } \\
\text { No. }\end{array}$ & Organ & $\begin{array}{c}\text { Positive } \\
\text { on } \\
\text { Ultra- } \\
\text { sound }\end{array}$ & $\begin{array}{c}\text { Positive } \\
\text { on } \\
\text { CT Scan }\end{array}$ & $\begin{array}{c}\text { No. of } \\
\text { Cases } \\
\text { Confirmed }\end{array}$ \\
\hline 1 & Spleen & 24 & 34 & 34 \\
\hline 2 & Liver & 22 & 34 & 34 \\
\hline 3 & Kidney & 20 & 24 & 24 \\
\hline 4 & Pancreas & 4 & 6 & 6 \\
\hline 5 & $\begin{array}{c}\text { Retroperitoneal } \\
\text { Haematoma }\end{array}$ & 2 & 6 & 6 \\
\hline 6 & Urinary Bladder & 0 & 2 & 2 \\
\hline 7 & Mesentery & 0 & 6 & 6 \\
\hline 8 & Bowel & 0 & 2 & 2 \\
\hline 9 & $\begin{array}{c}\text { Pleural } \\
\text { Collection }\end{array}$ & 14 & 16 & 16 \\
\hline 10 & $\begin{array}{c}\text { Psoas } \\
\text { Haematoma }\end{array}$ & 4 & 8 & 8 \\
\hline 11 & Ureter & 0 & 2 & 2 \\
\hline 12 & Adrenal Gland & 2 & 4 & 4 \\
\hline 13 & Uterus & 2 & 2 & 2 \\
\hline \multicolumn{5}{|c|}{$\begin{array}{l}\text { Table 3: Distribution of Patients } \\
\text { According to Organ Injury }(n=100\end{array}$} \\
\hline
\end{tabular}

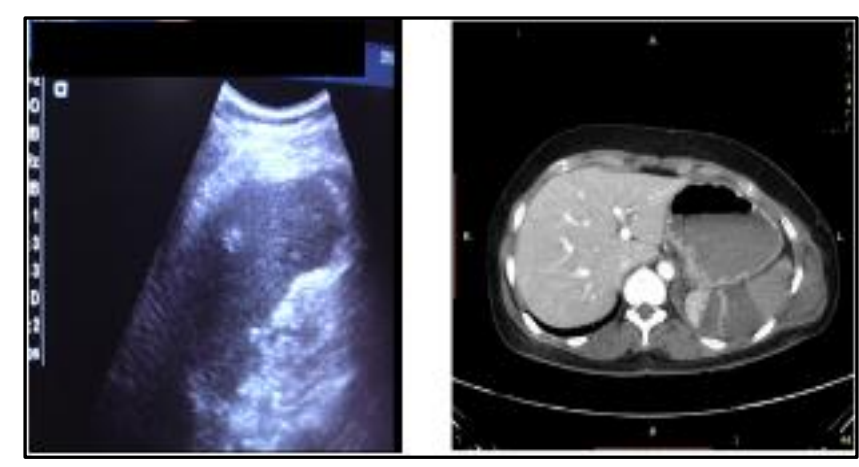

Image 1: USG and CT showing Splenic Contusion of the Same Patient 


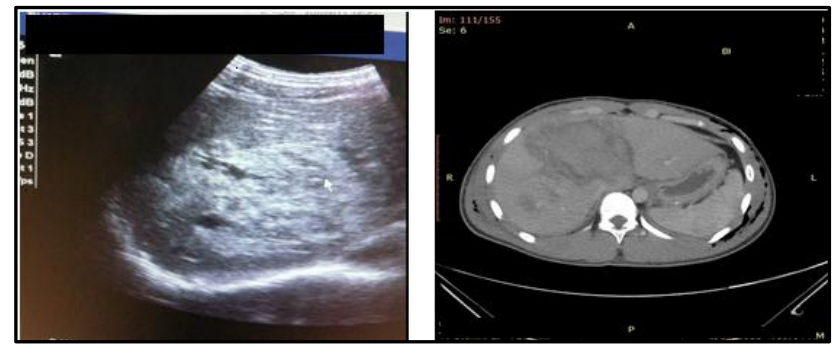

Image 2: USG and CT showing Contusion of Right Lobe of Liver of the Same Patient

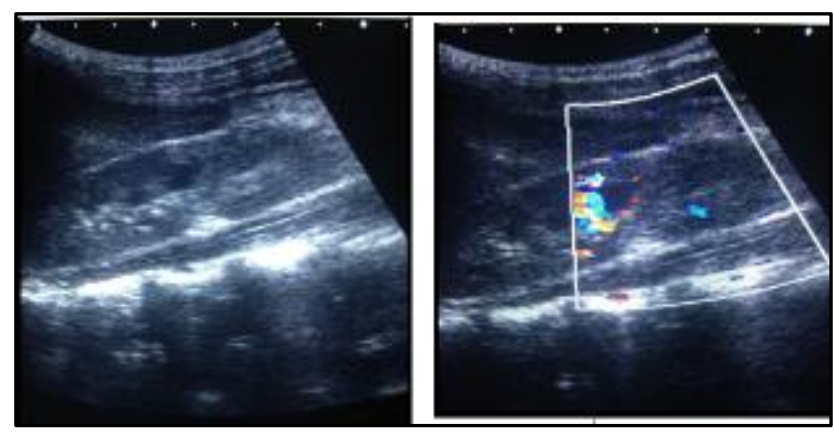

Image 3: USG showing Right Renal Lower Pole Contusion with Perinephric Haematoma with Reduced Perfusion

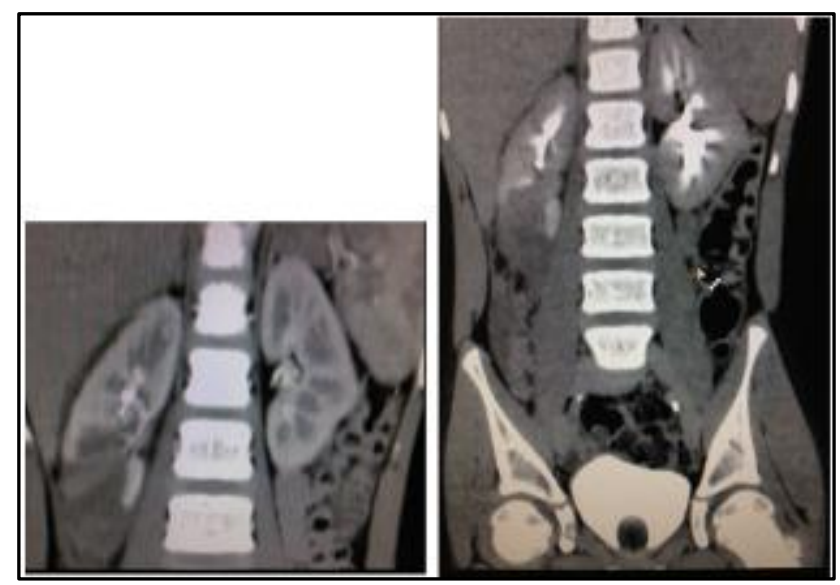

Image 4: CT showing Right Renal Lower Pole Contusion (Grade III Injury) of the Same Patient

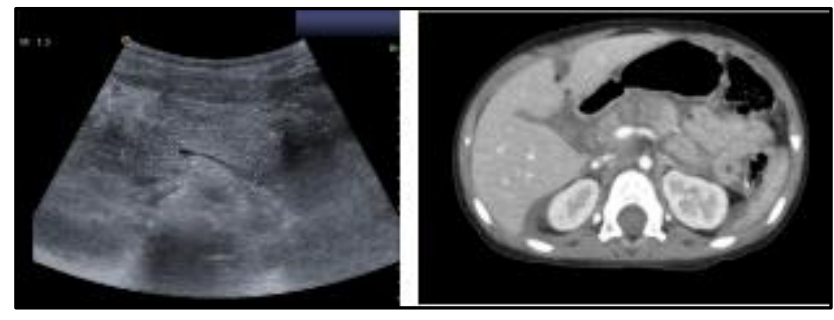

Image 5: USG showing Bulky, Oedematous Pancreas with Contusion and CT showing Pancreatic Fracture of the Same Patient

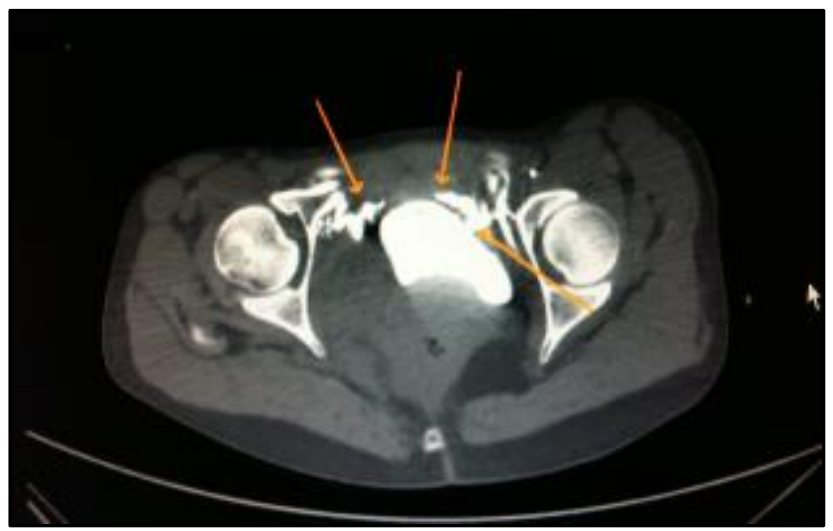

Image 6: CT showing Extra-Peritoneal Bladder Rupture, USG was Normal

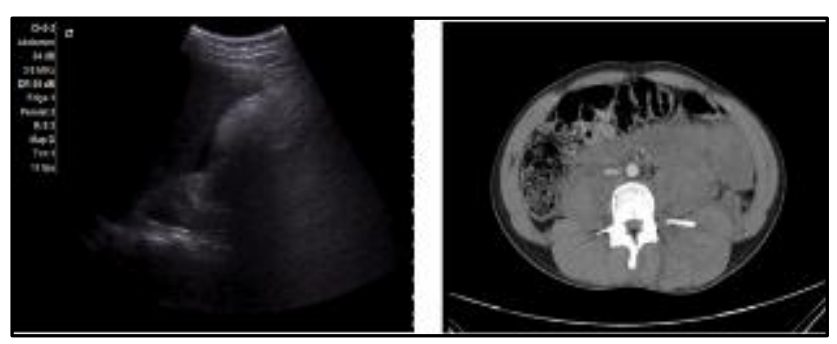

Image 7: USG showing Free Fluid in Morrison's Pouch and CT showing Retroperitoneal Haematoma of the Same Patient

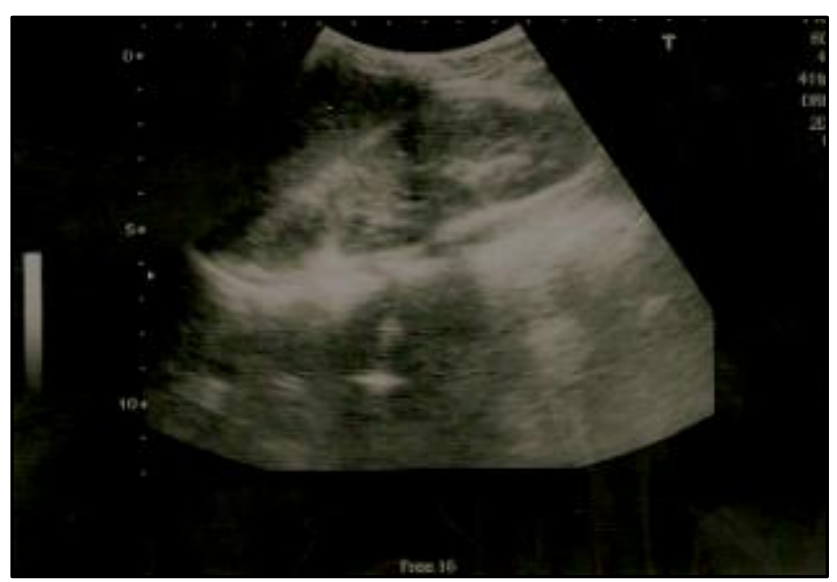

Image 8: USG showing Enlarged Hypoechoic Right Adrenal Gland

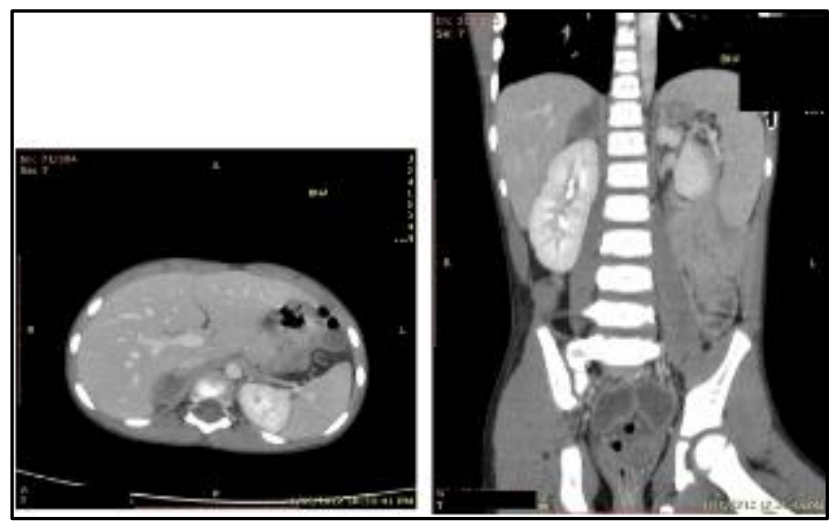

Image 9: CT showing Right Adrenal Gland Haematoma of the Same Patient 


\section{DISCUSSION}

In this study, a male predominance was found with male:female ratio of 3.5:1, which was also noted by William Pevec, Andres Peitzman, Anthony Udekwu et al and Srisussadaporn S. $(7,8)$

Fifty two percent (52\%) patients were in the age group of 21-40 years, the most active span of life, when people are prone for injuries, also demonstrated by Stuart E. Mirvis, Nancy O. Whitley, David R. Gens. $(9,10)$

The commonest mode of trauma was road traffic accident accounting for $66 \%$ of total cases. This is similar to findings by Srisussadaporn S.(8)

In this study, spleen and liver were the most common organs injured followed by kidney, which was similar to study by Barry D. Toombs, Richard G. Lester, Yoram Ben Menachem et al.(11)

In this study USG showed sensitivity of $100 \%$, specificity of $62.5 \%$ and overall diagnostic accuracy of $94 \%$ as compared to that of CT, which showed $100 \%$ sensitivity, $100 \%$ specificity and diagnostic accuracy of $100 \%$ for detection of free intraperitoneal fluid, which were very well comparable with other studies by Paolo Lucciarini, Schmuel Katz, Sattam S. Lingawi, Vivian W. Wing, Paul A. Kearney, William Pevec and S. Srisussadapom. $(8,12,13,14,15,16)$

In this study USG showed sensitivity of $68.8 \%$, specificity of $80 \%$ and overall diagnostic accuracy of $70 \%$ as compared to CT which showed $97.7 \%$ sensitivity, $100 \%$ specificity and overall diagnostic accuracy of $98 \%$ for detection of abdominal organ injuries, which were very well comparable with other studies by Paolo Lucciarini, Schmuel Katz, Sattam S. Lingawi, Vivian W. Wing, Paul A. Kearney, William Pevec and S. Srisussadapom. $(8,12,13,14,15,16)$

\section{CONCLUSION}

Ultrasound is an efficient imaging modality in the initial evaluation of patients with blunt abdominal trauma. But CT is the superior diagnostic modality. CT scan thoroughly scrutinizes entire abdomen including retroperitoneum with additional assessment of thoracic trauma and bony pelvic trauma. Hence, CT increases diagnostic confidence and influences management decision.

\section{REFERENCES}

1. Sutton D. A textbook of radiology and imaging. $7^{\text {th }}$ edn. vol. 1. India: Elsevier 2009:691-702.
2. Neish AS, Taylor GA, Lund DP, et al. Effect of CT information on the diagnosis and management of acute abdominal injury in children. Radiology 1998; 206 (2):327-31.

3. Scalea TM, Rodriguez A, Chiu WC, et al. FAST consensus conference committee. Result from an international consensus conference. J Trauma 1999;46(3):466-72.

4. Goldbergs BB, Goodman GA, Clearfield HR. Evaluation of ascites by ultrasound. Radiology 1970;96(1):15-22.

5. Federle MP. Computed tomography of blunt abdominal trauma. RCNA 1983;21(3):461-75.

6. Federle MP, Kaiser JA, McAninch JW, et al. The role of computed tomography in renal trauma. Radiology 1981;141:455-60.

7. Pevec WC, Peitzman AB, Udekwu AO, et al. Computed tomography in the evaluation of blunt abdominal trauma. Surgery Gynaecology \& Obstetrics 1991;173(4):262-7.

8. Srisussadaporn S. CT scan in blunt abdominal trauma. Injury 1993;24(8):514-44.

9. Mirvis SE, Whitley NO, Gens DR. Blunt splenic trauma in adults: CT based classification and correlation with prognosis and treatment. Radiology 1989;171(1):33-9.

10. Rumack CM, Wilson SR, Charboneay JW. Eds. Diagnostic ultrasound. vol 1. $3^{\text {rd }}$ edn. Missouri: Mosby-Year Book Inc 1992:137-9.

11. Toombs BD, Lester RG, Menachem YB, et al. Computed tomography in blunt abdominal trauma. RCNA 1981;19(1):17-35.

12. Lucciarini $P, O$ 'fner $D$, Weber $F$, et al. Ultrasonography in the initial evaluation \& follow up of blunt abdominal injury. Surgery 1993;114(3):506-12.

13. Katz S, Lazar L, Rathaus V, et al. Can ultrasonography replace computed tomography in the initial assessment of children with blunt abdominal trauma? J Paediatric Surgery 1996;31(5):649-51.

14. Lingawi SS, Buckley AR. Focused abdominal ultrasonography in patient with trauma. Radiology 2000;217(2):426-9.

15. Wing VW, Federle MP, Morris JA, et al. The clinical impact of computed tomography for blunt abdominal trauma. AJR 1985;145(6):1191-4.

16. Kearney PA, Vahey T, Burney RE, et al. Computerized tomography and diagnostic peritoneal lavage in blunt abdominal trauma. Arch Surg 1989;124(3):344-7. 